\title{
Chá da tarde: criando uma rede de apoio entre as discentes de cursos de Computação
}

\author{
Vanessa F. Dantas, Renata V. de Figueiredo \\ Universidade Federal da Paraíba (UFPB) \\ \{vanessa, renata\} adcx.ufpb.br
}

\begin{abstract}
Since girls are a minority in Computer Science courses, they usually do not feel comfortable and motivated to proceed in this area. This present work report how an annual event could help to integrate students better, creating a space for discussions related to important and everyday subjects, not only technical ones.
\end{abstract}

Resumo. Por serem minoria em cursos de Computação, nem sempre as meninas se sentem à vontade e motivadas a prosseguir na carreira. O presente trabalho relata a realização de um evento anual como uma iniciativa para promover maior integração entre as alunas, abrindo espaço para discussão de temas, nem sempre técnicos, que estão presentes em seus cotidianos.

\section{Introdução}

Os indicadores de ingresso e permanência de mulheres nos cursos de Ciências Exatas têm se mostrado bastante reduzidos e em queda. Segundo Lima (2013), a concentração de homens em cursos de Ciência da Computação chega a 79,9\% em alguns casos. Os dados do CENSO 2014 compilados pelo INEP e publicados pela SBC (2014) mostram que a quantidade de mulheres matriculadas em cursos de Tecnologia da Informação (TI) caiu de $24,10 \%$ para $15,27 \%$ entre 2001 e 2014.

Essa baixa presença de mulheres nos cursos superiores da área de Computação acaba trazendo novos desafios para aquelas que tentam se capacitar. Relatos de alunas, professoras e profissionais atuantes na área apontam que o fato de não encontrar outras mulheres que estejam passando pelas mesmas questões que elas causa um sentimento de solidão e fragilidade diante dos obstáculos que surgem. Além disso, algumas comentam que tentam se masculinizar para serem aceitas pelo gênero dominante, abrindo mão de suas vaidades e renegando o universo feminino. Tudo isso também contribui para um aumento nos números de evasão, que são bastante altos em todo o Brasil (SBC, 2014).

Juliano e Yunes (2014) descrevem a importância de construir redes de apoio para que as pessoas se fortaleçam, se apoiem, se sintam menos vulneráveis, e construam estratégias para superar crises. Construir redes de apoio para alunas dos cursos da área de TI parece ser uma boa estratégia para combater algumas possíveis causas de evasão.

O presente trabalho descreve uma iniciativa de discentes dos cursos de Licenciatura em Ciência da Computação e Bacharelado em Sistemas de Informação do Campus IV da Universidade Federal da Paraíba (UFPB) no sentido de criar uma rede de apoio feminina nesses cursos a partir de um evento anual. A Seção 2 descreve a metodologia usada para a realização das edições do evento, e a Seção 3 revela alguns 
resultados já percebidos desde 2015. Por fim, a Seção 4 contém algumas considerações finais e indicações de trabalhos futuros.

\section{Metodologia}

A UFPB oferece dois cursos na área de Computação: Licenciatura em Ciência da Computação e Bacharelado em Sistemas de Informação. Por estar situada em um campus de interior, a universidade costuma receber ingressantes de várias cidades da Paraíba. Muitos deles acabam saindo da casa de suas famílias e se mudando para Rio Tinto, cidade em que está situado o Campus IV, acumulando novas responsabilidades que exigem uma maturidade que eles nem sempre têm. São comuns relatos de solidão, saudade de casa, e dificuldades de adaptação, especialmente das meninas, que costumam ser poucas a cada semestre, e acabam fazendo amizade apenas com meninos.

Percebendo que as alunas dos dois cursos não se conheciam bem, e muitas vezes nem as meninas de um mesmo curso eram próximas, algumas discentes tiveram a ideia de realizar uma tarde de atividades de integração e bate-papo, e convidaram todas as alunas e professoras para participar.

O primeiro encontro de garotas na Computação do Campus IV da UFPB aconteceu em 15 de abril de 2015 e reuniu aproximadamente 30 participantes. A sala foi decorada em tons de rosa para receber as participantes, e cada uma foi convidada a se apresentar e falar um pouco sobre sua experiência na graduação. Em seguida, foram formadas equipes para realizar brincadeiras como colocar as instruções de um código na sequência correta, e programar em pares para resolver problemas simples. Ao final, foi servido um lanche e muitas fotos foram tiradas registrando a alegria de todas em estarem juntas naquele evento. A Figura 1 resume alguns desses momentos.

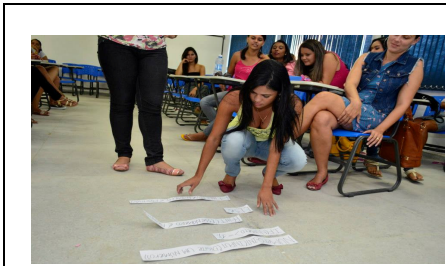

Ordenando código

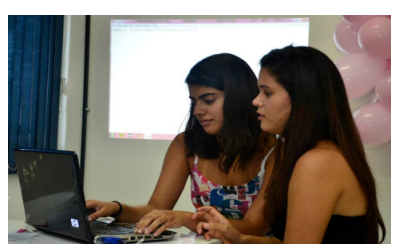

Programando em pares

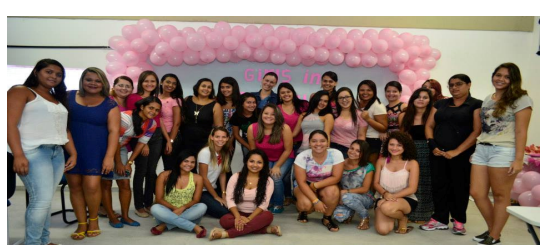

Participantes e decoração

Figura 1: Primeiro encontro de garotas na Computação

A repercussão desse primeiro evento foi excelente, pois tanto alunas quanto professoras perceberam a importância de unir as meninas dos cursos e tornar o ambiente agradável. Pela primeira vez, todas se sentiram fazendo parte de uma mesma rede de apoio, ouvindo experiências semelhantes às suas e criando laços de amizade. Muitas ficaram impressionadas com a quantidade de garotas que havia nos cursos, pois estavam acostumadas a ver apenas duas ou três por semestre, dando a impressão de que eram poucas. Enxergarem-se como um grupo maior deu um novo ânimo a todas.

Percebendo os resultados dessa iniciativa discente, as professoras que participaram perceberam que poderiam levar a ideia adiante na forma de um projeto com foco em dar suporte às alunas de ambos os cursos e promover uma mudança cultural no campus. No ano seguinte, surgiu o projeto IT Girls, cujo impacto na comunidade já foi discutido em trabalhos publicados em eventos acadêmicos e em apresentações em vários Estados do país (ALVES et. al. 2017) (DANTAS et. al. 2016). 
Em 19 de maio de 2016, foi realizada a segunda edição do evento, dessa vez com o nome de Chá da Tarde (ITea Girls). A ideia foi promover um encontro de mulheres para tratar de assuntos sérios, mas sem perder a graciosidade e a feminilidade até então pouco valorizadas no meio acadêmico dos cursos de Computação. Mantendo a inspiração no primeiro encontro realizado, foi montada uma mesa em tons de rosa com arranjos florais e louça de porcelana para que as participantes pudessem tirar fotos e guardar lembranças do evento.

Inicialmente, foi realizada uma dinâmica em que todas ficaram em pé formando um círculo, e cada uma teve que se apresentar e jogar um rolo de barbante para outra participante. Nas falas, as meninas iam percebendo que as dificuldades que sentem ao entrar na universidade são praticamente as mesmas, e que por elas não se conhecerem ou não se apoiarem, muitas vezes passavam por tudo sozinhas. Ao final da dinâmica, havia uma trama de conexões entre todas, simbolizando a rede de apoio feminina que vinha sendo construída no campus desde o evento inicial.

A programação do encontro continuou com uma apresentação sobre o conceito de feminismo, e outra sobre os rótulos associados ao universo masculino e ao universo feminino. As participantes foram convidadas a expor suas opiniões em cartazes espalhados pela sala, e diferentes visões de mundo foram identificadas. Percebeu-se que o machismo e a religiosidade ainda são muito influentes nas famílias das alunas que frequentam o campus, o que acentua os conflitos delas em estarem na área tecnológica. Muitas meninas ainda tinham uma visão do feminismo como um movimento radical, e que ia de encontro à visão da mulher submissa e passiva de alguns trechos bíblicos. Inclusive, foi comentado que o termo feminista estava sendo usado como ofensa pelos meninos do campus. A Figura 2 contém o registro dos principais momentos do chá da tarde realizado.

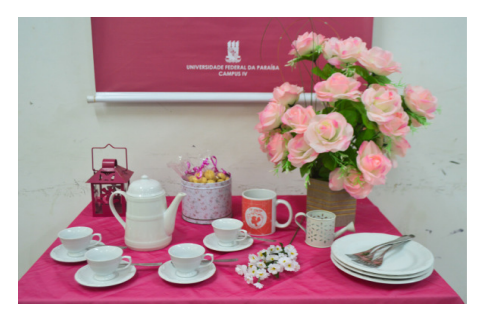

Mesa decorada para fotos

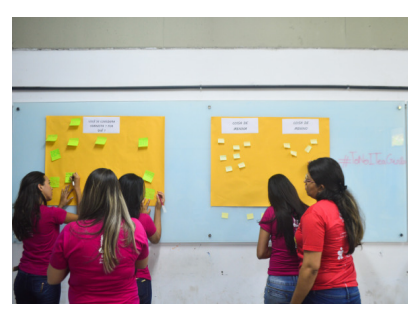

Expondo opiniões

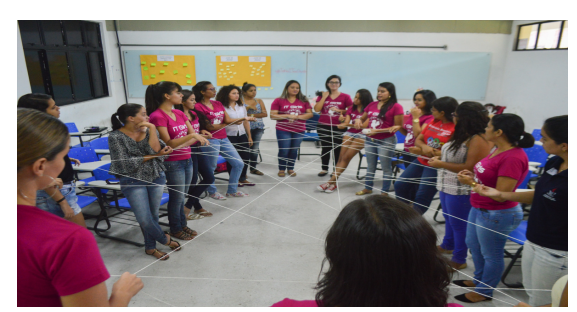

Dinâmica da teia de barbantes

Figura 2: Chá da Tarde realizado em 2016

O Chá da Tarde de 2017 ocorreu em 04 de agosto. Tendo como ponto de partida a diversidade e a importância da individualidade, logo no início foram oferecidos vários tipos de crachá, com a logomarca do projeto adaptada para diferentes estilos, e cada participante pode escolher e personaliza-los a seu gosto. Além disso, novas cores foram incluídas na decoração, fugindo do padrão rosa predominante nas outras edições.

Em seguida, cada garota foi convidada a relatar um dia muito bom e outro muito ruim que tinha vivido na universidade, e várias semelhanças entre elas foram percebidas, fortalecendo a identificação do grupo. Foram então apresentadas brevemente histórias de mulheres inspiradoras ao redor do mundo, evidenciando também diferenças e semelhanças. O ponto alto do chá foi uma conversa sobre sororidade em que todas aprenderam um pouco mais sobre como poderiam se ajudar e se apoiar mutuamente no dia a dia. Alguns destaques da terceira edição do evento podem ser vistos na Figura 3. 


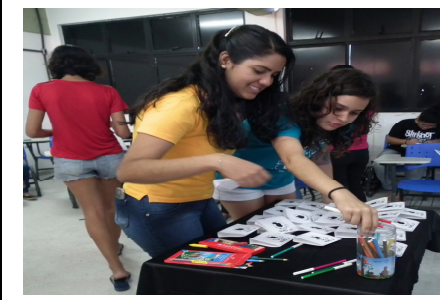

Escolha dos crachás

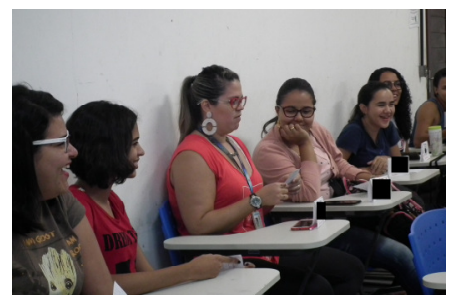

Relatos de experiências

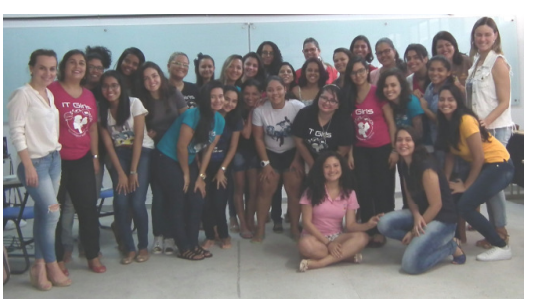

Inspiração e Sororidade

Figura 3: Chá da Tarde realizado em 2017

As informações resumidas sobre todas as edições realizadas até o momento podem ser vistas na Tabela 1.

Tabela 1. Resumo das edições do Chá da Tarde

\begin{tabular}{|c|c|c|c|l|}
\hline Edição & Data & $\begin{array}{c}\text { Alunas } \\
\text { participantes }\end{array}$ & $\begin{array}{c}\text { Professoras } \\
\text { participantes }\end{array}$ & \multicolumn{1}{c|}{ Atividades Realizadas } \\
\hline $1^{\mathrm{a}}$ & $15 / 04 / 2015$ & 25 & 02 & $\begin{array}{l}\text { - Dinâmica de apresentação } \\
\text { - Programação em Pares } \\
\text { - Quebra-cabeça de código }\end{array}$ \\
\hline $2^{\mathrm{a}}$ & $19 / 05 / 2016$ & 20 & 03 & $\begin{array}{l}\text { - Dinâmica do barbante (teia) } \\
\text { - Discussão sobre feminismo e } \\
\text { sobre rótulos femininos e } \\
\text { masculinos }\end{array}$ \\
\hline $3^{\mathrm{a}}$ & $04 / 08 / 2017$ & 27 & 04 & $\begin{array}{l}\text { - Escolha e customização de } \\
\text { crachás } \\
\text { - Relato: um dia muito bom, um } \\
\text { dia muito ruim } \\
\text { - Apresentação sobre mulheres } \\
\text { inspiradoras } \\
\text { - Discussão sobre sororidade }\end{array}$ \\
\hline
\end{tabular}

\section{Resultados}

É perceptível a aproximação que as alunas dos dois cursos passaram a ter após a realização desses eventos. Muitos são os relatos de como o projeto e o incentivo das colegas e professoras impediu que elas desistissem da área. Há inclusive casos de alunas de diferentes semestres e cursos que passaram a compartilhar moradia na cidade, mostrando que muitas barreiras foram quebradas. Há também exemplos de alunas que se tornaram mães durante a graduação e tiveram o apoio de suas colegas para retomar os estudos e cuidar das crianças.

A rede de apoio formada tem permitido inclusive que sejam identificadas situações de assédio e misoginia na universidade. Por se sentirem mais apoiadas e ouvidas, as alunas têm procurado a ajuda de outras alunas e também de suas professoras para fazer denúncias e pedir que providências sejam tomadas. Em outros contextos, é possível que essas alunas acabassem abandonando a vida acadêmica.

Também é importante destacar que as alunas integrantes do projeto participam ativamente do planejamento e da realização dos eventos, desenvolvendo competências como liderança e senso de trabalho coletivo. Da decoração do ambiente à apresentação 
dos temas, as alunas são incentivadas a assumir responsabilidades, o que faz com que se sintam mais confiantes e mais comprometidas com as outras alunas.

\section{Considerações Finais e Trabalhos Futuros}

As alunas dos cursos de Computação precisam ser incentivadas a permanecerem na universidade, uma vez que enfrentam várias dificuldades. É importante que elas se conheçam, e que tenham espaços de escuta e de troca de experiências. As calouras podem encontrar nas veteranas exemplos de superação, e podem se espelhar em profissionais de sucesso para terem cada vez mais incentivo para atuar na área.

A realização dos Chás da Tarde se mostrou uma iniciativa muito válida para atingir vários desses objetivos. Eventos similares costumam acontecer dentro de outros projetos que incentivam a presença e permanência feminina na tecnologia, mas nem sempre são documentados. É importante, além da divulgação e postagem de fotos, a descrição das atividades e análise dos resultados para que as ideias se propaguem.

Também é relevante deixar claro que esses encontros anuais não são os únicos momentos de interação na universidade. Desde o evento inicial, têm sido realizadas com frequência palestras, exibições de filmes e discussões para tratar questões pertinentes, e tudo isso acabou provocando mudanças culturais no campus.

Como trabalhos futuros, espera-se que os eventos possam atingir cada vez mais alunas, professoras, e também outras profissionais do campus, uma vez que a participação de psicólogas e assistentes sociais pode contribuir muito para ajudar a lidar com as questões mais subjetivas. Também existe o interesse de avaliar o impacto dessa rede de apoio na permanência das alunas nos cursos, considerando depoimentos (pesquisa qualitativa), e também indicadores acadêmicos como tempo de conclusão. Espera-se encontrar dados para avaliar o impacto dessa rede de apoio nas estudantes nos nossos cursos, e compartilhá-los em futuras publicações.

\section{Referências}

ALVES, G.; SILVA, J.; DANTAS, R.; DANTAS, V.; FIGUEIREDO, R.; SOUZA, G. Usando técnicas de aprendizagem colaborativa para incentivar o ensino-aprendizagem de programação entre as alunas de cursos de Computação. In: $11^{\circ}$ WIT - Women in Information Technology, 2017, São Paulo. XXXVII Congresso da Sociedade Brasileira de Computação.

DANTAS, V.; FIGUEIREDO, R.; SOUZA, G,; NASCIMENTO, R.R; NASCIMENTO, A.C.; MARTINS, B. Um Estudo Inicial Sobre As Alunas Ingressantes no Curso de Licenciatura em Ciência da Computação da Universidade Federal da Paraíba. In: $10^{\circ}$ WIT - Women in Information Technology, 2016, Porto Alegre. XXXVI Congresso da Sociedade Brasileira de Computação.

INEP - Censo da Educação Superior 2014. Disponível em $<$ http://sistemascensosuperior.inep.gov.br/censosuperior_2014/>. Acessado em 05 de abril de 2018.

JULIANO, M. C. C.; YUNES, M. A. M. Reflexões sobre rede de apoio social como mecanismo de proteção e promoção de resiliência. Ambiente \& Sociedade, v. 17, n. 3, 2014

SBC - Educação Superior em Computação - Estatísticas - 2014 Disponível em http://www.sbc.org.br/documentos-da-sbc/summary/133-estatisticas/1007-estatisticas-daeducacao-superior-2014. Acessado em 05 de abril de 2018. 